OPEN ACCESS

Edited by:

Jaroslaw T. Hepel,

Rhode Island Hospital, United States

Reviewed by:

Yukinori Matsuo,

Kyoto University, Japan

Zhiyong Yuan,

Tianjin Medical University Cancer

Institute and Hospital, China

*Correspondence:

Xue Meng

mengxue5409@126.com

Jinming Yu

sdyujinming@163.com

Specialty section

This article was submitted to

Radiation Oncology,

a section of the journal

Frontiers in Oncology

Received: 04 October 2019 Accepted: 16 December 2019

Published: 24 January 2020

Citation:

Cai G, Liang S, Li C, Meng X and Yu J (2020) Left Ventricular Systolic Dysfunction Is a Possible Independent Risk Factor of Radiation Pneumonitis

in Locally Advanced Lung Cancer Patients. Front. Oncol. 9:1511. doi: 10.3389/fonc.2019.01511

\section{Left Ventricular Systolic Dysfunction Is a Possible Independent Risk Factor of Radiation Pneumonitis in Locally Advanced Lung Cancer Patients}

\author{
Guoxin Cai ${ }^{1,2}$, Shuai Liang ${ }^{2}$, Chuanbao $\mathrm{Li}^{3}$, Xue Meng ${ }^{2 *}$ and Jinming $\mathrm{Yu}^{1,2 *}$ \\ ${ }^{1}$ Department of Radiation Oncology, School of Medicine, Shandong University, Jinan, China, ${ }^{2}$ Department of Radiation \\ Oncology, Shandong Cancer Hospital Affiliated to Shandong First Medical University, Shandong Academy of Medical \\ Science, Jinan, China, ${ }^{3}$ Department of Emergency, Chest Pain Center, Qilu Hospital of Shandong University, Jinan, China
}

Objectives: To assess the association between left ventricular (LV) systolic and diastolic dysfunction and grade $\geq 2$ radiation pneumonitis (RP) for locally advanced lung cancer patients receiving definitive radiotherapy.

Materials and Methods: A retrospective analysis was carried out for 260 lung cancer patients treated with definitive radiotherapy between 2015 and 2017. RP was evaluated according to Radiation Therapy Oncology Group (RTOG) toxicity criteria. Logistic regression analysis, 10-fold cross validation, and external validation were performed. The prediction model's discriminative performance was evaluated using the area under the receiver operating characteristic curve (AUC), and calibration of the model was assessed by the Hosmer-Lemeshow test and the calibration curve.

Results: Within the first 6 months after radiotherapy, 70 patients (26.9\%) developed grade $\geq 2$ RP. Reduced left ventricular ejection fraction (LVEF) before radiotherapy was detected in 53 patients (20.4\%). The odds ratio (OR) of developing RP for patients with LVEF $<50 \%$ was 3.42 [ $p<0.001,95 \%$ confidence interval (Cl), 1.85-6.32]. Multivariate analysis showed that forced expiratory volume in the first second/forced vital capacity (FEV1/FVC), LVEF, Eastern Cooperative Oncology Group (ECOG) performance status, chemotherapy, and mean lung dose (MLD) were significantly associated with grade $\geq 2 \mathrm{RP}$. The AUC of a model including the above five variables was $0.835(95 \% \mathrm{Cl}$, $0.778-0.891)$ on 10-fold cross validation and 0.742 (95\% Cl, $0.633-0.851)$ on the external validation set. The $p$-value for the Hosmer-Lemeshow test was 0.656 on 10 -fold cross validation and 0.534 on the external validation set.

Conclusion: LV systolic dysfunction is a possible independent risk factor for RP in locally advanced lung cancer patients receiving definitive radiotherapy.

Keywords: left ventricular ejection fraction, radiation pneumonitis, left ventricular systolic dysfunction, locally advanced lung cancer, definitive radiotherapy 


\section{INTRODUCTION}

Concurrent chemoradiotherapy is a standard treatment regimen for patients with inoperable locally advanced non-small cell lung cancer (NSCLC) (1) or small cell lung cancer (2). Radiation pneumonitis (RP) is an important dose-limiting complication of thoracic radiotherapy, with clinical symptoms of dyspnea, a non-productive cough, and occasionally low-grade transient fevers (3). Risk factors for RP are various, including lung volume receiving $\geq 20 \mathrm{~Gy}$, mean lung dose (MLD), chemotherapy, age, former or current smoker, chronic obstructive pulmonary disease, and interstitial lung disease (4-9).

Previous preclinical (10-12) and clinical (13) studies have demonstrated that heart irradiation increases the risk of radiation-induced pulmonary dysfunction. The possible mechanism is that heart radiation directly leads to perivascular fibrosis and myocardial damage and therefore increases enddiastolic pressure, contributing to left ventricular (LV) diastolic dysfunction, which further leads to pulmonary interstitial edema (12), suggesting a detrimental effect of reduced ventricular function on lung tissue. Nalbantov et al. (14) demonstrated cardiac comorbidity was an independent risk factor for developing radiation-induced lung toxicity in lung cancer patients receiving definitive radiotherapy. However, cardiac comorbidity is only a qualitative indicator that couldn't quantify detailed LV systolic and diastolic function. Semrau et al. (15) found that for patients with inoperable NSCLC receiving concurrent chemoradiotherapy, left ventricular ejection fraction (LVEF) $\leq 50 \%$ had no significant association with grades III and IV RP according to the Common Toxicity Criteria. But the overall incidence of RP was fairly low: only three out of 130 patients $(2.3 \%)$, therefore it couldn't accurately reflect the association between baseline cardiac function and RP.

In the present study, we aimed to evaluate the relationship between LV systolic and diastolic dysfunction and grade $\geq 2 \mathrm{RP}$.

\section{MATERIALS AND METHODS}

\section{Patients}

A retrospective analysis was carried out for patients with stages IIA-IIIB lung cancer and Eastern Cooperative Oncology Group (ECOG) performance status of zero to two treated with definitive radiotherapy at Qilu Hospital of Shandong University between January 2015 and December 2017. Those who received palliative, preoperative or post-operative radiotherapy, could not complete radiotherapy regimen, or had secondary primary tumor were excluded from this study. Tumor was staged according to the American Joint Committee of Cancer seven edition criteria.

\footnotetext{
Abbreviations: NSCLC, non-small cell lung cancer; RP, radiation pneumonitis; LV, left ventricular; LVEF, left ventricular ejection fraction; ECOG, Eastern Cooperative Oncology Group; MLD, mean lung dose; MHD, mean heart dose; FEV1/FVC, forced expiratory volume in the first second/forced vital capacity; LAVI, left atrial volume index; $\mathrm{e}^{\prime}$, lateral early diastolic mitral annular velocity; $\mathrm{E} / \mathrm{A}$, the ratio of early diastolic transmitral flow velocity to late diastolic transmitral flow velocity; AUC, area under the receiver operating characteristic curve; HR, hazard ratio; CI, confidence interval; HFmrEF, heart failure with mid-range ejection fraction.
}

Before treatment, contrast-enhanced thoracic and abdominal computed tomography, whole-body bone scan, and brain MRI were performed for all patients. Fluorodeoxyglucose positron emission tomography/computed tomography was optional for enrolled patients. Biopsy methods included bronchoscopy, thoracoscopy, or percutaneous transthoracic needle biopsy. Patients in the external validation set were collected from Shandong Provincial Hospital between 2015 and 2017. This study was approved by the Ethics Committee of Qilu Hospital of Shandong University and Shandong Provincial Hospital, and informed consents were obtained from all included individuals.

\section{Treatment}

Treatment-planning computed tomography scans using intravenous contrast were performed for all patients. The radiotherapy was delivered at 2 Gy per fraction daily and five fractions per week by using linear accelerators with an energy of $6-\mathrm{MV}$ or $10-\mathrm{MV} \mathrm{X}$-ray. The prescribed dose ranged from 60 to 70 Gy. Radiation techniques included three-dimensional conformal radiation therapy or intensity-modulated radiation therapy. We set normal tissue tolerance dose-limits according to the National Comprehensive Cancer Network guidelines (16): maximum dose to spinal cord $\leq 50 \mathrm{~Gy}$, lung volume receiving $\geq 20 \mathrm{~Gy} \leq 35 \%$, lung volume received $\geq 5 \mathrm{~Gy} \leq 65 \%$, MLD $\leq$ $20 \mathrm{~Gy}$, heart volume received $\geq 40 \mathrm{~Gy} \leq 80 \%$, mean heart dose (MHD) $\leq 35 \mathrm{~Gy}$, and esophagus mean dose $\leq 34 \mathrm{~Gy}$. Most patients received concurrent or sequential chemotherapy. For patients with NSCLC, the regimens consisted of two cycles of platinum-based chemotherapy. For patients with small cell lung cancer, the regimens were two cycles of etoposide plus platinum. Detailed information about treatment plan was collected from medical records.

\section{Evaluation of Cardiac Function}

All patients underwent a comprehensive transthoracic echocardiographic evaluation using GE Vivid 7 (GE Healthcare, Horten, Norway) and pulmonary function testing within 1 week before receiving radiotherapy. Consistent with the American Society of Echocardiography guidelines (17), echocardiography including conventional pulsed-wave Doppler and tissue Doppler echocardiography was performed to acquire transvalvular flow and tissue Doppler recordings. LVEF was used to assess LV systolic function. A cut-off of 50\% was regarded as the normal limits for LVEF. For assessing diastolic function, an algorithm recently put forward by Mitter et al. (18) was used. This algorithm uses left atrial volume index (LAVI) $>28 \mathrm{ml} / \mathrm{m}^{2}$ and age-related reduced lateral early diastolic mitral annular velocity $\left(\mathrm{e}^{\prime}\right)$ to check for presence of diastolic dysfunction. The key variables for grading of LV diastolic dysfunction include the ratio of early diastolic transmitral flow velocity to late diastolic transmitral flow velocity (E/A), $\mathrm{e}^{\prime}, \mathrm{LAVI}$, and E-wave deceleration time. The details for grading of $\mathrm{LV}$ diastolic function are as follows: normal: E/A $>0.8, \mathrm{e}^{\prime}$ normal for age, normal LAVI; grade I: $\mathrm{E} / \mathrm{A}<0.8$, reduced $\mathrm{e}^{\prime}$ for age; grade II: E/A $>0.8$, reduced $\mathrm{e}^{\prime}$ for age, LAVI $>28 \mathrm{ml} / \mathrm{m}^{2}$; grade III: E/A $>1.5$, reduced $\mathrm{e}^{\prime}$ for age, E-wave deceleration time $<140 \mathrm{~ms}$, LAVI $>28 \mathrm{ml} / \mathrm{m}^{2}$. Pulmonary and cardiac comorbidities were defined as a recorded historical 
TABLE 1 | Patient characteristics.

\begin{tabular}{|c|c|c|}
\hline \multirow[t]{2}{*}{ Characteristic } & \multicolumn{2}{|c|}{ Patients (\%) } \\
\hline & Training set & Validation set \\
\hline \multicolumn{3}{|l|}{ Gender } \\
\hline Male & $172(66.1)$ & 88 (73.3) \\
\hline Female & $88(33.9)$ & $32(26.7)$ \\
\hline \multicolumn{3}{|l|}{ Current or former smoker } \\
\hline Yes & $144(55.4)$ & $62(51.7)$ \\
\hline No & $116(44.6)$ & $58(48.3)$ \\
\hline \multicolumn{3}{|l|}{ Pulmonary comorbidity } \\
\hline Yes & 58 (22.3) & $27(22.5)$ \\
\hline No & $202(77.7)$ & $93(77.5)$ \\
\hline \multicolumn{3}{|l|}{ Cardiac comorbidity } \\
\hline Yes & $53(20.4)$ & $22(18.3)$ \\
\hline No & 207 (79.6) & $98(81.7)$ \\
\hline \multicolumn{3}{|l|}{${ }^{*} \mathrm{NYHA}$ classification } \\
\hline Grade 1 & $13(24.5)$ & $7(31.8)$ \\
\hline Grade 2 & $23(43.4)$ & $9(40.9)$ \\
\hline Grade 3 & $17(32.1)$ & $6(27.3)$ \\
\hline \multicolumn{3}{|l|}{ ECOG Performance status } \\
\hline 0 & 95 (36.5) & $50(41.7)$ \\
\hline 1 & $148(56.9)$ & $61(50.8)$ \\
\hline 2 & $17(6.6)$ & $9(7.5)$ \\
\hline \multicolumn{3}{|l|}{ Baseline dyspnea score } \\
\hline 0 & $108(41.5)$ & $54(45.0)$ \\
\hline 1 & $125(48.1)$ & $53(44.2)$ \\
\hline 2 & $27(10.4)$ & $13(10.8)$ \\
\hline \multicolumn{3}{|l|}{ Histology } \\
\hline Squamous cell carcinoma & $98(37.7)$ & $45(37.5)$ \\
\hline Adenocarcinoma & $110(42.3)$ & $45(37.5)$ \\
\hline Small cell carcinoma & $52(20.0)$ & $30(25.0)$ \\
\hline \multicolumn{3}{|l|}{ Tumor location } \\
\hline Upper lobe & $142(54.6)$ & $72(60.0)$ \\
\hline Lower/middle lobe & $118(45.4)$ & $48(40.0)$ \\
\hline \multicolumn{3}{|l|}{ cT-stage } \\
\hline T2 & $59(22.7)$ & $32(26.7)$ \\
\hline T3 & $181(72.0)$ & $82(68.3)$ \\
\hline T4 & $20(5.3)$ & $6(5.00)$ \\
\hline \multicolumn{3}{|l|}{ cN-stage } \\
\hline NO & $21(8.1)$ & $13(10.8)$ \\
\hline N1 & $126(48.5)$ & $51(42.5)$ \\
\hline N2 & $96(36.9)$ & $43(35.8)$ \\
\hline N3 & $17(6.5)$ & $13(10.9)$ \\
\hline \multicolumn{3}{|l|}{ TNM stage } \\
\hline$\| \mathrm{A}$ & $25(9.6)$ & $10(8.3)$ \\
\hline IIB & 35 (13.5) & $19(15.8)$ \\
\hline IIIA & $171(65.8)$ & $78(65.0)$ \\
\hline IIIB & $29(11.1)$ & $13(10.8)$ \\
\hline \multicolumn{3}{|l|}{ Treatment modality } \\
\hline Concurrent chemotherapy & $131(50.4)$ & 64 (53.3) \\
\hline Sequential chemotherapy & $73(28.1)$ & $18(15.0)$ \\
\hline No chemotherapy & $56(21.5)$ & $38(31.7)$ \\
\hline Chemotherapy regimens & & \\
\hline
\end{tabular}

(Continued)
TABLE 1 | Continued

\begin{tabular}{lcc}
\hline \multirow{2}{*}{ Characteristic } & \multicolumn{2}{c}{ Patients (\%) } \\
\cline { 2 - 3 } & Training set & Validation set \\
\hline NSCLC & $208(80.0)$ & $90(75.0)$ \\
cisplatin/carboplatin + etoposide & $66(25.4)$ & $26(21.7)$ \\
cisplatin/carboplatin + paclitaxel & $58(22.3)$ & $20(16.7)$ \\
cisplatin/carboplatin + pemetrexed & $50(19.2)$ & $21(17.5)$ \\
$\quad$ cisplatin/carboplatin + vinorelbine & $20(7.7)$ & $11(9.1)$ \\
$\quad$ cisplatin/carboplatin + gemcitabine & $14(5.4)$ & $12(10.0)$ \\
SCLC & $52(20.0)$ & $30(25.0)$ \\
$\quad$ cisplatin/carboplatin + etoposide & $52(20.0)$ & $30(25.0)$ \\
Radiotherapy technique & & \\
3D-CRT & $104(40.0)$ & $51(42.5)$ \\
IMRT & $156(60.0)$ & $69(57.5)$ \\
& & Median $(S D)$ \\
Age at lung cancer diagnosis, year & $64(8.48)$ & $63(8.92)$ \\
Prescribed radiation dose, Gy & $64(2.53)$ & $64(3.25)$ \\
Mean lung dose, Gy & $16.65(6.01)$ & $15.75(5.81)$ \\
FEV1/FVC, \% & $75.80(12.04)$ & $77.65(13.43)$ \\
FS, \% & $33.62(5.17)$ & $34.68(5.26)$ \\
SV, ml & $56.83(11.09)$ & $59.49(10.41)$ \\
LVEF, \% & $60(8.22)$ & $55(6.28)$ \\
E/A & $1.03(0.19)$ & $1.10(0.18)$ \\
E/e' & $6.09(3.42)$ & $6.23(3.84)$ \\
\hline
\end{tabular}

NYHA, New York Heart Association; ECOG, Eastern Cooperative Oncology Group; 3DCRT, three-dimensional conformal radiation therapy; IMRT, intensity-modulated radiation therapy; $S D$, standard deviation; FEV1/FVC, forced expiratory volume in the first second/forced vital capacity; FS, fractional shortening; SV, stroke volume; LVEF, left ventricular ejection fraction; $E / A$, the ratio of early diastolic transmitral flow velocity to late diastolic transmitral flow velocity; E/e', the ratio of early diastolic transmitral flow velocity to early diastolic mitral annular velocity.

${ }^{*}$ The NYHA classification was assessed only for patients with cardiac comorbidity.

treatment of any pulmonary and cardiac disorders at hospital before the start of radiotherapy, irrespective of their severity. Given that the assessment method for LV diastolic function by Mitter et al. (18) was not applicable to tachycardia, bradycardia, atrioventricular block, arrhythmia, mitral annular calcification, mitral valve prosthesis, any mitral stenosis, and $\geq 3+$ mitral regurgitation, patients with these cardiac comorbidities were excluded from our study. Before treatment, baseline dyspnea score [Common Terminology Criteria for Adverse Events version 3.0 (19)] was assessed for all patients and New York Heart Association classification was reassessed for patients with cardiac comorbidity, with baseline dyspnea score $>2$ and New York Heart Association grade $>3$ being excluded. A cut-off of $70 \%$ was regarded as the normal limits for forced expiratory volume in the first second/forced vital capacity (FEV1/FVC).

\section{Evaluation of Pulmonary Toxicity and Follow-Up}

The primary endpoint was grade $\geq 2$ RP. Early RP usually occurs 1-6 months after radiotherapy, whereas late lung fibrosis usually occurs 6-24 months after radiotherapy $(9,20,21)$. Because we 
focused on early RP, we used 6 months as the cut-off for diagnosis. $\mathrm{RP}$ was graded according to the Common Terminology Criteria for Adverse Events v3.0. A diagnosis of RP was based on clinical symptoms and/or radiograghic changes and was determined with consensus by at least two radiation oncologists. Radiograghic changes include ground-glass opacities and/or consolidation and nodular and focal consolidative opacities within the treatment filed. Radiographic changes in RP outside the treatment portals may also appear (22). Clinical symptoms include dyspnea, dry cough, and low-grade fever (4). Cases difficult to diagnose were referred to a respiratory physician or cardiologist to exclude other diseases. Patients were evaluated by radiation oncologists fortnightly during radiotherapy and once a month thereafter until 6 months after radiotherapy. CT scans were performed at each follow-up visit.

\section{Statistical Analysis}

Univariate and multivariate analyses were performed on the training set and validated on the validation set. Variables which were statistically significant in univariate analysis were included in multivariate analysis. The association between variables and $\mathrm{RP}$ in univariate analyses was assessed using a chi-square test. Variables significantly associated with grade $\geq 2 \mathrm{RP}$ in multivariate analysis were put into a model to predict grade $\geq 2$ RP. Internal validation was performed with 10 -fold crossvalidation for the training set. External validation was performed with data from Shandong Provincial Hospital. The model's discriminative ability was evaluated using the area under the receiver operating characteristic curve (AUC), and calibration of the model was assessed by the Hosmer-Lemeshow test and the calibration curve (23). $P$-values for the difference between AUC for the 10-fold cross validation or the external validation and $\mathrm{AUC}=0.05$ (random model) were calculated using 1,000 bootstrap samples. For all analyses, $p<0.05$ were considered statistically significant. The univariate and multivariate logistic regression analyses were performed by SPSS Statistics Version 23.0 (IBM Corporation, Armonk, NY, USA), and the evaluation methods of the model performance were performed using $\mathrm{R}$ (version 3.6.1).

\section{RESULTS}

Two hundred and sixty patients and one hundred and twenty patients were enrolled in the training and validation set, respectively. Seventy patients $(26.9 \%)$ on the training set and 33 patients $(27.5 \%)$ on the validation set developed grade $\geq 2 \mathrm{RP}$ within 6 months after radiotherapy. Patient characteristics on the training and validation set are listed in Table $\mathbf{1}$.

In univariate analysis, pulmonary comorbidity, FEV1/FVC, cardiac comorbidity, LVEF, LV diastolic dysfunction, ECOG performance status, concurrent or sequential chemotherapy, and MLD were significantly associated with grade $\geq 2$ RP (Table 2 ). FEV1/FVC [hazard ratio (HR), 6.02; 95\% confidence interval (CI), 2.13-17.00; $p=0.001$ ], LVEF (HR, 3.38; 95\% CI, $1.43-$ 7.96; $p=0.005$ ), ECOG performance status (HR, 4.38; 95\% CI, $1.76-10.89 ; p=0.001)$, concurrent or sequential chemotherapy (HR, 3.08; 95\% CI, 1.40-6.78; $p=0.005$ ), and MLD (HR, 5.08;
TABLE 2 | Univariate and multivariate logistic regressions analysis for grade $\geq 2$ radiation pneumonitis.

\begin{tabular}{|c|c|c|c|c|}
\hline \multirow[t]{2}{*}{ Characteristic } & \multicolumn{2}{|c|}{ Univariable analysis } & \multicolumn{2}{|c|}{ Multivariate analysis } \\
\hline & HR (95\% Cl) & $p$-value & HR (95\% Cl) & $p$-value \\
\hline Gender (Male vs. Female) & $\begin{array}{c}1.16 \\
(0.65-2.09)\end{array}$ & 0.617 & & \\
\hline Age ( $\geq 64$ vs. $<64$ ), year & $\begin{array}{c}1.35 \\
(0.77-2.36)\end{array}$ & 0.290 & & \\
\hline Current or former smoker & $\begin{array}{c}1.78 \\
(1.03-3.10)\end{array}$ & 0.039 & $\begin{array}{c}1.33 \\
(0.63-2.82)\end{array}$ & 0.461 \\
\hline Pulmonary comorbidity & $\begin{array}{c}3.56 \\
(1.92-6.59)\end{array}$ & $<0.001$ & $\begin{array}{c}1.13 \\
(0.38-3.33)\end{array}$ & 0.825 \\
\hline FEV1/FVC (<70 vs. $\geq 70$ ), \% & $\begin{array}{c}5.33 \\
(2.90-9.81)\end{array}$ & $<0.001$ & $\begin{array}{c}6.02 \\
(2.13-17.00)\end{array}$ & 0.001 \\
\hline Cardiac comorbidity & $\begin{array}{c}3.21 \\
(1.71-6.05)\end{array}$ & $<0.001$ & $\begin{array}{c}1.18 \\
(0.45-3.10)\end{array}$ & 0.730 \\
\hline LVEF (<50 vs. $\geq 50), \%$ & $\begin{array}{c}3.42 \\
(1.85-6.32)\end{array}$ & $<0.001$ & $\begin{array}{c}3.38 \\
(1.43-7.96)\end{array}$ & 0.005 \\
\hline LV diastolic dysfunction & $\begin{array}{c}2.35 \\
(1.25-4.43)\end{array}$ & 0.007 & $\begin{array}{c}1.70 \\
(0.72-4.00)\end{array}$ & 0.224 \\
\hline $\begin{array}{l}\text { ECOG performance status } \\
(\geq 1 \text { vs. } 0)\end{array}$ & $\begin{array}{c}6.55 \\
(2.97-14.42)\end{array}$ & $<0.001$ & $\begin{array}{c}4.38 \\
(1.76-10.89)\end{array}$ & 0.001 \\
\hline $\begin{array}{l}\text { Tumor location (Upper lobe } \\
\text { vs. Lower/middle lobe) }\end{array}$ & $\begin{array}{c}0.72 \\
(0.41-1.24)\end{array}$ & 0.235 & & \\
\hline c-T stage ( $\geq$ T3 vs. <T3) & $\begin{array}{c}1.40 \\
(0.70-2.79)\end{array}$ & 0.336 & & \\
\hline $\mathrm{c}-\mathrm{N}$ stage $(\geq \mathrm{N} 2$ vs. $<\mathrm{N} 2)$ & $\begin{array}{c}1.33 \\
(0.77-2.30)\end{array}$ & 0.313 & & \\
\hline TNM stage ( $\geq$ IIIA vs. $<I I I A)$ & $\begin{array}{c}1.14 \\
(0.59-2.21)\end{array}$ & 0.702 & & \\
\hline $\begin{array}{l}\text { Concurrent or sequential } \\
\text { chemotherapy }\end{array}$ & $\begin{array}{c}2.66 \\
(1.47-4.81)\end{array}$ & 0.001 & $\begin{array}{c}3.08 \\
(1.40-6.78)\end{array}$ & 0.005 \\
\hline $\begin{array}{l}\text { Radiotherapy modality } \\
\text { (3D-CRT vs. IMRT) }\end{array}$ & $\begin{array}{c}1.27 \\
(0.73-2.22)\end{array}$ & 0.392 & & \\
\hline $\begin{array}{l}\text { Prescribed radiation dose } \\
\text { ( } \geq 64 \text { vs. }<64) \text {, Gy }\end{array}$ & $\begin{array}{c}1.53 \\
(0.88-2.66)\end{array}$ & 0.128 & & \\
\hline $\begin{array}{l}\text { Mean lung dose ( } \geq 16.5 \text { vs. } \\
<16.5 \text { ), Gy }\end{array}$ & $\begin{array}{c}3.39 \\
(1.86-6.17)\end{array}$ & $<0.001$ & $\begin{array}{c}5.08 \\
(2.39-10.82)\end{array}$ & $<0.001$ \\
\hline $\begin{array}{l}\text { Mean heart dose ( } \geq 12 \text { vs. } \\
<12 \text { ), Gy }\end{array}$ & $\begin{array}{c}1.34 \\
(0.77-2.33)\end{array}$ & 0.297 & & \\
\hline
\end{tabular}

FEV1/FVC, forced expiratory volume in the first second/forced vital capacity; LVEF, left ventricular ejection fraction; LV, left ventricular; ECOG, Eastern Cooperative Oncology Group; 3D-CRT, three-dimensional conformal radiation therapy; IMRT, intensitymodulated radiation therapy; HR, hazard ratio; $\mathrm{Cl}$, confidence interval.

95\% CI, 2.39-10.82; $p<0.001)$ remained significant difference in multivariate analysis. The odds ratio of developing RP for patients with LVEF $<50$ was 3.42 (95\% CI, $1.85-6.32 ; p<0.001)$ on the training set and 3.00 (95\% CI, 1.13-7.97; $p=0.023)$ on the validation set (Table 3 ).

Variables including FEV1/FVC, LVEF, ECOG performance status, concurrent or sequential chemotherapy, and MLD were put into a model to predict grade $\geq 2 \mathrm{RP}$ on 10 -fold cross validation and the external validation set. The model demonstrated good discrimination (AUC 0.835, 95\% CI, 0.778$0.891 ; p<0.001)$ and the Hosmer-Lemeshow test confirmed good calibration ( $p=0.656$ ) on 10 -fold cross validation. On 
TABLE 3 | Comparison of the risk of radiation pneumonitis between LVEF $\geq 50 \%$ and $<50 \%$.

\begin{tabular}{|c|c|c|c|c|c|c|c|c|}
\hline & \multicolumn{2}{|c|}{ Training set } & \multicolumn{2}{|c|}{ Validation set } & \multicolumn{2}{|c|}{ Training set } & \multicolumn{2}{|c|}{ Validation set } \\
\hline & & & & & \multicolumn{4}{|c|}{ Baseline dyspnea $=0$} \\
\hline & Grade 0-1 RP & Grade $\geq 2$ RP & Grade 0-1 RP & Grade $\geq 2$ RP & Grade 0-1 RP & Grade $\geq 2$ RP & Grade 0-1 RP & Grade $\geq 2 \mathrm{RP}$ \\
\hline LEVF $\geq 50 \%$ & 159 & 42 & 76 & 23 & 83 & 13 & 37 & 10 \\
\hline LEVF $<50 \%$ & 31 & 28 & 11 & 10 & 7 & 5 & 4 & 3 \\
\hline Odds ratio $(95 \% \mathrm{Cl})$ & \multicolumn{2}{|c|}{$3.42(1.85-6.32)$} & \multicolumn{2}{|c|}{$3.00(1.13-7.97)$} & \multicolumn{2}{|c|}{$4.56(1.26-16.53)$} & \multicolumn{2}{|c|}{$2.78(0.53-14.48)$} \\
\hline$p$-value & \multicolumn{2}{|c|}{$<0.001$} & \multicolumn{2}{|c|}{0.023} & \multicolumn{2}{|c|}{0.014} & \multicolumn{2}{|c|}{0.213} \\
\hline
\end{tabular}

$L V E F$, left ventricular ejection fraction; $C l$, confidence interval; $R P$, radiation pneumonitis.

the external validation set, the model remained strong predictive performance, maintaining an AUC of 0.742 (95\% CI, 0.633$0.851 ; p<0.001)$ and a Hosmer-Lemeshow test $p$-value of 0.534 . The nomograms, calibration curves, and receiver operator characteristic curves for the model predicting grade $\geq 2 \mathrm{RP}$ on 10 fold cross validation and the external validation set are shown in Figures 1-3, respectively.

In subgroup analysis, for patients with baseline dyspnea score of $0(n=108)$, reduced LVEF (HR, 4.67; 95\% CI, $1.01-21.48$; $p=0.048)$ was still significantly associated with an increased hazard of grade $\geq 2$ RP (Table 4). However, these findings were not confirmed on the validation set, with a corresponding $p$-value of 0.213 (Table 3). Furthermore, compared with LVEF $\geq 50 \%$, LVEF $<40 \%$ (HR, 2.37; 95\% CI, 1.38-9.41; $p=0.009)$ was significantly associated with grade $\geq 2 \mathrm{RP}$, but LVEF in the range of $40-49 \%$ (HR, 2.37; 95\% CI, 0.58-9.61; $p=0.228$ ) did not significantly increase the risk of grade $\geq 2 \mathrm{RP}$ (data not shown). Similar findings were noted on the external validation set: LVEF $<40 \%$ (HR, 5.46; 95\% CI, 1.14-26.12; $p=0.034$ ) could increase the risk of grade $\geq 2 \mathrm{RP}$ but LVEF of $40-49 \%$ (HR, 2.39; $95 \% \mathrm{CI}$, $0.36-15.75 ; p=0.365$ ) couldn't (data not shown). For grade $\geq 2$ diastolic dysfunction, it was still not a significant factor (HR, 2.81; 95\% CI, $0.81-9.78 ; p=0.104$ ) to predict the occurrence of grade $\geq 2$ RP (data not shown).

\section{DISCUSSION}

In the present study, we assessed the relationship between LV systolic and diastolic function at baseline and grade $\geq 2 \mathrm{RP}$, demonstrating that LVEF $<50 \%$ was a possible independent risk factor of grade $\geq 2 \mathrm{RP}$ for locally advanced lung cancer patients treated with definitive radiotherapy. This may be a surprising finding, for there have been no reports to assess the relationship between LV systolic and diastolic dysfunction and RP. These data may inform radiation oncologists that for patients with LV systolic dysfunction, especially for those with LVEF $<40 \%$, individualized radiotherapy and frequent monitoring of pulmonary status after radiotherapy should be considered. Given that previous studies had demonstrated that heart irradiation was an independent risk factor for RP (12), we used a chi-square test to assess whether MHD might be a confounding factor, and therefore patients with higher MHD were actually those who developed RP; a $p$-value of 0.297 suggested that there had been no relationship between MHD and grade $\geq 2 \mathrm{RP}$.

LVEF, calculated by end-diastolic volume-end-systolic volume/end-diastolic volume, is the most validated and commonly used echocardiographic measure of systolic function (24). A cut-off of $50 \%$ is usually defined as a normal limit for LVEF (25). LVEF is a reliable method to measure both LV contractile function and structure and to identify heart failure therapeutic phenotypes. It is also the best current method of assessing pathologic remodeling in heart failure (26). Ventricular systolic dysfunction begins with a reduction in systolic pump function following a loss of muscle cells, a decrease in myocardial contractility, and/or structural changes of the myocardium with an increase in interstitial fibrosis (27). The reduced systolic pump function induces several compensatory mechanisms including the Frank-Starling principle, neurohormonal activation of the sympathetic nervous system, and the renin-angiotensinaldosterone system increases the strength of subsequent ventricular contraction and the stroke volume. However, the compensatory mechanisms can also lead to an enlargement of ventricle and an increase in end-diastolic pressure $(27,28)$. The adverse effects of these compensatory mechanisms are reduced by subsequent myocardial hypertrophy, activation of the baroreceptor reflex, and release of atrial natriuretic peptide (27). However, with the reduction of cardiovascular reserve, ventricular contraction, and stroke volume, LVEF is reduced and end diastolic volume is increased, which ultimately could lead to dyspnea and other congestive symptoms (28). The detailed mechanism regarding reduced LVEF on the development of RP is not clear, possibly related to the detrimental effect of LV systolic dysfunction on lung tissue, and it should be elucidated in the future. However, using new diagnostic techniques of myocardial deformation, several studies have shown subtle changes in systolic function that couldn't be detected by ejection fraction (29-31). Additionally, some studies demonstrated that there was a slow but progressive decline in LVEF in patients with diastolic heart failure, and these patients would eventually be diagnosed with heart failure with reduced $\operatorname{LVEF}(32,33)$. Therefore, there may be inaccuracies in evaluating LV systolic function by LVEF, and thus more sensitive measure for evaluating LV systolic function, such as global longitudinal strain (34), may be needed in the future study.

According to the 2016 European Society of Cardiology guidelines (25), heart failure with LVEF of $40-49 \%$ is named 


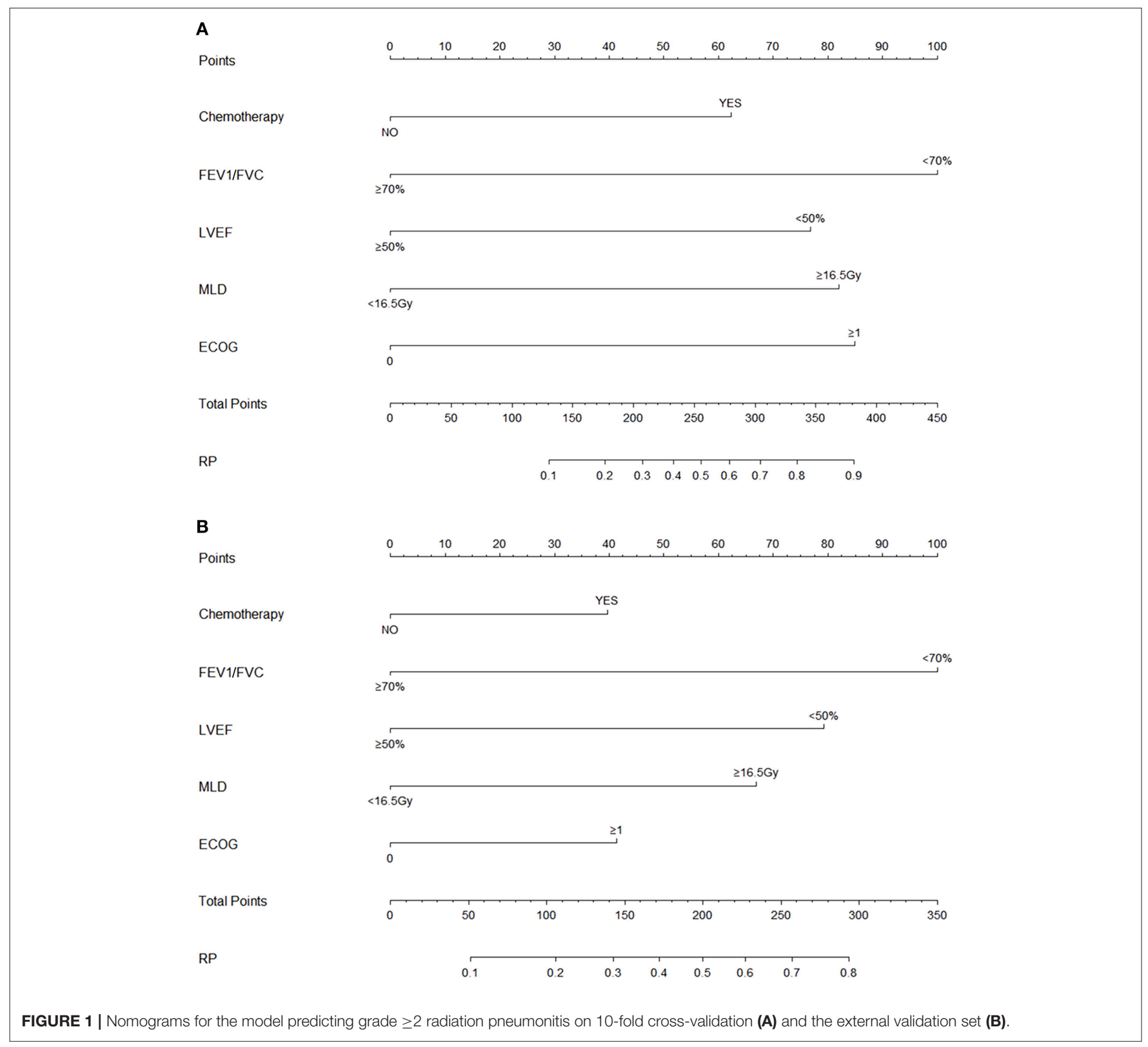

with heart failure with mid-range ejection fraction (HFmrEF). The underlying pathophysiology of HFmrEF is not completely clear (35). The 2016 European Society of Cardiology guidelines suggest that patients with HFmrEF probably have mild systolic dysfunction as well as diastolic dysfunction (25). A recent study divided HFmrEF patients into three subgroups: HFmrEF improved (prior LVEF < 40\%), HFmrEF deteriorated (prior LVEF > 50\%), and HFmrEF unchanged (prior LVEF 40-50\%) and found heterogeneity in epidemiology, pathophysiology, and clinical outcomes between these subgroups (36). In our study, we found that compared with $\mathrm{LVEF} \geq 50 \%$, LVEF in the range of $40-49 \%$ couldn't significantly increase the risk of grade $\geq 2$ RP, possibly due to the heterogeneity between patients with mid-range LVEF. Additionally, this study demonstrated that for patients with baseline dyspnea score of $0(n=108)$, reduced LVEF was still significantly associated with an increased hazard of grade $\geq 2 \mathrm{RP}$. However, these findings were not confirmed on the validation set, suggesting that the relationship between reduced LVEF and grade $\geq 2$ RP for asymptomatic patients is not clear and corresponding further studies with large population size are needed to clearly determine this relationship.

Seeking a suitable diagnostic criteria for LV diastolic dysfunction doesn't seem to be an easy task. The diagnostic criteria of LV diastolic dysfunction by echocardiography is changing. The 2009 consensus guidelines from the American Society of Echocardiography and the European Association of Echocardiography on evaluating diastolic dysfunction use three variables: septal and lateral $\mathrm{e}^{\prime}$ velocity and LAVI to determine 

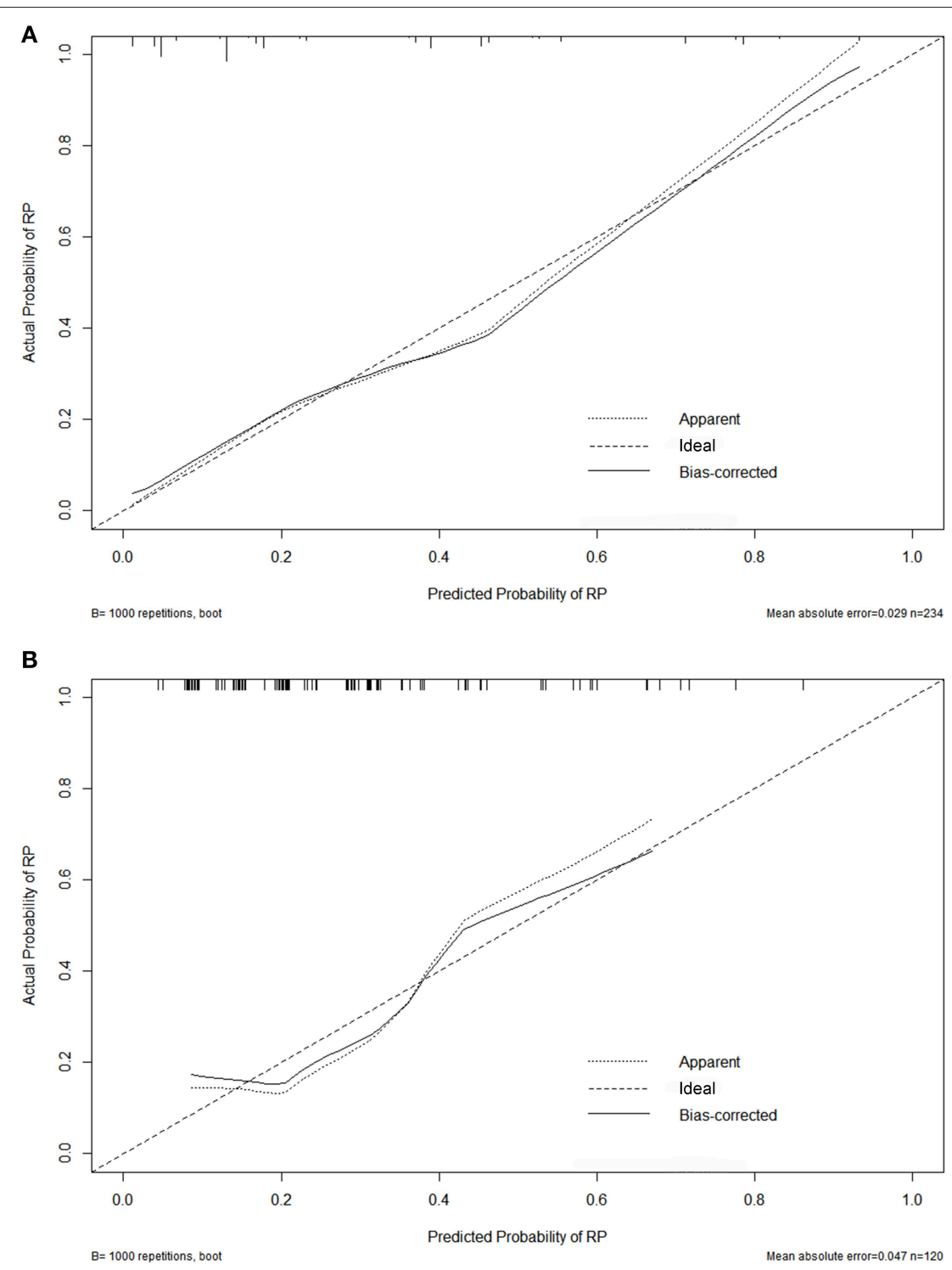

FIGURE 2 | Calibration curves for the nomogram on 10-fold cross-validation (A) and the external validation set (B).

whether patients have diastolic dysfunction (37). According to the 2009 consensus guidelines, there should be eight $(2 \times 2$ $\times 2$ ) possible combined results from the three variables, but the guidelines include only three combined results, ignoring the other five, which could lead to many indeterminate assessments for diastolic function. The 2009 consensus guidelines provide a low sensitivity of $47 \%$ for identifying diastolic dysfunction in heart failure with preserved ejection fraction patients (38). The updated 2016 joint guideline from the American Society of Echocardiography and the European Association of Cardiovascular Imaging selects four variables: annular e' velocity, average $\mathrm{E} / \mathrm{e}^{\prime}$ ratio, LAVI, and peak tricuspid regurgitation velocity to determine the presence of diastolic dysfunction (39). However, using this updated joint guideline to evaluate diastolic function could also create a situation that diastolic dysfunction is underdiagnosed. For example, if $50 \%$ of the above four variables are positive, then diastolic dysfunction would be considered indeterminate under this classification scheme. Additionally, increased peak TR velocity is not merely determined by an elevation in LV filling pressure, and can be caused by a pre-capillary component of pulmonary hypertension. Increased peak TR velocity caused by an elevation in LV filling pressure is seen in advanced stages of diastolic dysfunction. Therefore, patients with early diastolic dysfunction may be underdiagnosed (18). Mitter et al. (18) recently put forward a new algorithm for diagnosing diastolic dysfunction with Doppler echocardiography. Although this algorithm lacks validation in clinical practice, it selects commonly used variables to assess diastolic function from the commonly used 2009 consensus guidelines. Notably, this algorithm deems that a LAVI of $>28$ 

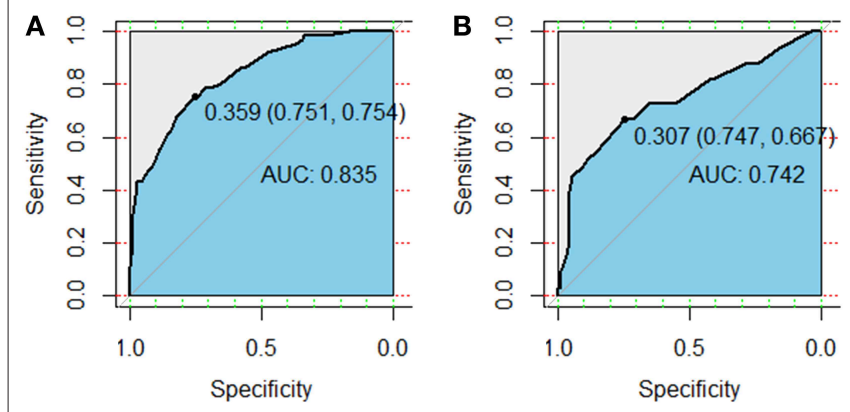

FIGURE 3 | Receiver operator characteristic (ROC) curves for the model predicting grade $\geq 2$ radiation pneumonitis on 10 -fold cross-validation $\mathbf{( A )}$ and the external validation set (B).

TABLE 4 | Multivariate logistic regressions analysis of grade $\geq 2$ radiation pneumonitis for patients with baseline dyspnea $=0$.

\begin{tabular}{|c|c|c|}
\hline \multirow[t]{2}{*}{ Characteristic } & \multicolumn{2}{|c|}{ Multivariate analysis } \\
\hline & HR $(95 \% \mathrm{Cl})$ & $p$-value \\
\hline Current or former smoker & $\begin{array}{c}1.52 \\
(0.42-5.52)\end{array}$ & 0.523 \\
\hline Pulmonary comorbidity & $\begin{array}{c}0.35 \\
(0.03-3.70)\end{array}$ & 0.380 \\
\hline FEV1/FVC (<70 vs. $\geq 70), \%$ & $\begin{array}{c}6.77 \\
(1.02-44.95)\end{array}$ & 0.048 \\
\hline Cardiac comorbidity & $\begin{array}{c}1.42 \\
(0.20-10.00)\end{array}$ & 0.723 \\
\hline LVEF (<50 vs. $\geq 50), \%$ & $\begin{array}{c}4.67 \\
(1.01-21.48)\end{array}$ & 0.048 \\
\hline LV diastolic dysfunction & $\begin{array}{c}0.90 \\
(0.13-6.27)\end{array}$ & 0.913 \\
\hline ECOG performance status ( $\geq 1$ vs. 0) & $\begin{array}{c}3.03 \\
(0.74-12.43)\end{array}$ & 0.124 \\
\hline Concurrent or sequential chemotherapy & $\begin{array}{c}2.38 \\
(0.61-9.32)\end{array}$ & 0.215 \\
\hline Mean lung dose ( $\geq 16.5$ vs. $<16.5$ ), Gy & $\begin{array}{c}6.77 \\
(1.02-44.95)\end{array}$ & 0.048 \\
\hline
\end{tabular}

FEV1/FVC, forced expiratory volume in the first second/forced vital capacity; LVEF, left ventricular ejection fraction; LV, left ventricular; ECOG, Eastern Cooperative Oncology Group; HR, hazard ratio; Cl, confidence interval.

$\mathrm{ml} / \mathrm{m}^{2}$ can suggest early diastolic dysfunction and that criteria for an abnormal lateral $e^{\prime}$ used to evaluate diastolic function should be population-based and age-related. Furthermore, this algorithm helps echocardiogram readers to distinguish pitfalls quickly, limiting adequate evaluation of diastolic function (18). Therefore, our study adopted this algorithm to assess LV diastolic function.

Cardiac comorbidity was also selected for the univariate analysis in our study. But unlike with Nalbantov et al. (14), we found that cardiac comorbidity was significantly associated with grade $\geq 2 \mathrm{RP}$ in univariate analysis but didn't remain significant difference in multivariate analysis, possibly due to a lack of timeliness for the history of cardiac comorbidity: preexisting cardiac disease couldn't represent the cardiac status on admission, and patients may have underlying cardiac disease on admission that was not previously discovered.

Previous studies have demonstrated that among the first-line chemotherapy regimens for lung cancer, paclitaxel, gemcitabine, and vinorelbine can lead to pulmonary toxicity $(40,41)$, and there was no sufficient evidence to confirm that other drugs can cause pulmonary toxicity. Therefore, we divided patients who used paclitaxel, gemcitabine, and vinblastine into one group and divided other patients into another group, investigating whether chemotherapy drugs that can cause pulmonary toxicity has an effect on the occurrence of RP. The results revealed that $p$-values for the training and validation sets were $0.364(\mathrm{HR}, 1.34 ; 95 \% \mathrm{CI}, 0.73-$ 2.41) and $0.286(\mathrm{HR}, 1.58 ; 95 \% \mathrm{CI}, 0.86-2.79)$, respectively (data not shown), indicating that there was no association between chemotherapy drugs that can cause pulmonary toxicity and RP.

There were several other limitations in this study. First, the retrospective nature may lead to a bias during patients' selection and inaccuracies of data. Second, the algorithm we used to evaluate diastolic dysfunction has not been validated clinically, and it may yield a low specificity for identifying diastolic dysfunction owing to the low normal limit of LAVI $\left(28 \mathrm{ml} / \mathrm{m}^{2}\right)$. Last, other biomarkers commonly used to evaluate cardiac function, such as brain natriuretic peptide and $\mathrm{N}$-terminal pro-brain natriuretic peptide (42), were not factored into this study. Newer echocardiographic parameters for assessing diastolic function, specifically left atrial strain $(43,44)$, have been reported in recent years. Therefore, further prospective studies with indicators more accurately reflecting LV systolic and diastolic functions are needed to confirm and broadly interpret the present findings.

In conclusion, LV systolic dysfunction is a possible independent risk factor of grade $\geq 2 \mathrm{RP}$ for locally-advanced lung cancer patients receiving definitive radiotherapy. Compared with $\mathrm{LVEF} \geq 50 \%$, LVEF $<40 \%$ is significantly associated with grade $\geq 2 \mathrm{RP}$, but LVEF in the range of 40 to $-49 \%$ couldn't increase the risk of grade $\geq 2 \mathrm{RP}$. For asymptomatic patients, it remains unclear whether systolic dysfunction has an effect on the development of grade $\geq 2 \mathrm{RP}$ and should be elucidated in the future.

\section{DATA AVAILABILITY STATEMENT}

The datasets generated for this study are available on request to the corresponding author.

\section{ETHICS STATEMENT}

The studies involving human participants were reviewed and approved by The Ethics Committee of Qilu Hospital of Shandong University, The Ethics Committee of Shandong Provincial Hospital. The patients/participants provided their written informed consent to participate in this study. Written informed consent was obtained from the individual(s) for the 
publication of any potentially identifiable images or data included in this article.

\section{AUTHOR CONTRIBUTIONS}

$\mathrm{XM}$ and JY contributed to the conception and design of the study. GC and CL organized the database. GC and SL performed the statistical analysis. GC and XM wrote the first draft of the manuscript. All authors contributed to manuscript revision, read and approved the submitted version.

\section{REFERENCES}

1. Aupérin A, Le Péchoux C, Rolland E, Curran WJ, Furuse K, Fournel P, et al. Meta-analysis of concomitant versus sequential radiochemotherapy in locally advanced non-small-cell lung cancer. J Clin Oncol. (2010) 28:218190. doi: 10.1200/JCO.2009.26.2543

2. Takada M, Fukuoka M, Kawahara M, Sugiura T, Yokoyama A, Yokota S, et al. Phase III study of concurrent versus sequential thoracic radiotherapy in combination with cisplatin and etoposide for limited-stage small-cell lung cancer: results of the Japan Clinical Oncology Group Study 9104. J Clin Oncol. (2002) 20:3054-60. doi: 10.1200/JCO.2002.12.071

3. Graves PR, Siddiqui F, Anscher MS, Movsas B. Radiation pulmonary toxicity: from mechanisms to management. Semin Radiat Oncol. (2010) 20:20107. doi: 10.1016/j.semradonc.2010.01.010

4. Hanania AN, Mainwaring W, Ghebre YT, Hanania NA, Ludwig M. Radiationinduced lung injury: assessment and management. Chest. (2019) 156:15062. doi: 10.1016/j.chest.2019.03.033

5. Tsujino K, Hashimoto T, Shimada T, Yoden E, Fujii O, Ota Y, et al. Combined analysis of V20, VS5, pulmonary fibrosis score on baseline computed tomography, and patient age improves prediction of severe radiation pneumonitis after concurrent chemoradiotherapy for locally advanced non-small-cell lung cancer. J Thorac Oncol. (2014) 9:98390. doi: $10.1097 /$ JTO.0000000000000187

6. Palma DA, Senan S, Tsujino K, Barriger RB, Rengan R, Moreno M, et al. Predicting radiation pneumonitis after chemoradiation therapy for lung cancer: an international individual patient data meta-analysis. Int $J$ Radiat Oncol Biol Phys. (2013) 85:444-50. doi: 10.1016/j.ijrobp.2012.04.043

7. Li F, Zhou Z, Wu A, Cai Y, Wu H, Chen M, et al. Preexisting radiological interstitial lung abnormalities are a risk factor for severe radiation pneumonitis in patients with small-cell lung cancer after thoracic radiation therapy. Radiat Oncol. (2018) 13:82. doi: 10.1186/s13014-018-1030-1

8. Torre-Bouscoulet L, Muñoz-Montaño WR, Martínez-Briseño D, LozanoRuiz FJ, Fernández-Plata R, Beck-Magaña JA, et al. Abnormal pulmonary function tests predict the development of radiation-induced pneumonitis in advanced non-small cell lung Cancer. Respir Res. (2018) 19:72. doi: 10.1186/s12931-018-0775-2

9. Dang J, Li G, Zang S, Zhang S, Yao L. Comparison of risk and predictors for early radiation pneumonitis in patients with locally advanced non-small cell lung cancer treated with radiotherapy with or without surgery. Lung Cancer. (2014) 86:329-33. doi: 10.1016/j.lungcan.2014.10.005

10. van Luijk P, Novakova-Jiresova A, Faber H, Schippers JM, Kampinga $\mathrm{HH}$, Meertens $\mathrm{H}$, et al. Radiation damage to the heart enhances early radiation-induced lung function loss. Cancer Res. (2005) 65:650911. doi: 10.1158/0008-5472.CAN-05-0786

11. van Luijk $P$, Faber $H$, Meertens $H$, Schippers JM, Langendijk JA, Brandenburg S, et al. The impact of heart irradiation on dose-volume effects in the rat lung. Int J Radiat Oncol Biol Phys. (2007) 69:5529. doi: 10.1016/j.ijrobp.2007.05.065

12. Huang EX, Hope AJ, Lindsay PE, Trovo M, El Naqa I, Deasy JO, et al. Heart irradiation as a risk of factor for radiation pneumonitis. Acta Oncol. (2011) 50:51-60. doi: 10.3109/0284186X.2010.521192

13. Ghobadi G, van der Veen S, Bartelds B, de Boer RA, Dickinson MG, de Jong JR, et al. Physiological interaction of heart and lung

\section{FUNDING}

This work was supported by the National Natural Science Foundation of China (Grant No. 81972864).

\section{ACKNOWLEDGMENTS}

We acknowledge Prof. Zhe Yang and Dr. Jing Qiao from the Department of Radiation Oncology, Shandong Provincial Hospital for their support in data acquisition.

in thoracic irradiation. Int J Radiat Oncol Biol Phys. (2012) 84:e63946. doi: 10.1016/j.ijrobp.2012.07.2362

14. Nalbantov G, Kietselaer B, Vandecasteele K, Oberije C, Berbee M, Troost E, et al. Cardiac comorbidity is an independent risk factor for radiation-induced lung toxicity in lung cancer patients. Radiother Oncol. (2013) 109:1006. doi: 10.1016/j.radonc.2013.08.035

15. Semrau S, Klautke G, Fietkau R. Baseline cardiopulmonary function as an independent prognostic factor for survival of inoperable nonsmall-cell lung cancer after concurrent chemoradiotherapy: a single-center analysis of 161 cases. Int J Radiat Oncol Biol Phys. (2011) 79:96104. doi: 10.1016/j.ijrobp.2009.10.010

16. Ettinger DS, Wood DE, Akerley W, Bazhenova LA, Borghaei H, Camidge DR, et al. Non-small cell lung cancer, version 1.2015. J Natl Compr Canc Netw. (2014) 12:1738-61. doi: 10.6004/jnccn.2014.0176

17. Quin $\sim_{\text {ones }} \mathrm{MA}$, Otto $\mathrm{CM}$, Stoddard $\mathrm{M}$, Waggoner A, Zoghbi WA. Doppler Quantification Task Force of the Nomenclature and Standards Committee of the American Society of Echocardiography. Recommendations for quantification of Doppler echocardiography: a report from the Doppler Quantification Task Force of the Nomenclature and Standards Committee of the American Society of Echocardiography. J Am Soc Echocardiogr. (2002) 15:167-84. doi: 10.1067/mje.2002.120202

18. Mitter SS, Shah SJ, Thomas JD. A test in context: E/A and E/e' to assess diastolic dysfunction and LV filling pressure. J Am Coll Cardiol. (2017) 69:1451-64. doi: 10.1016/j.jacc.2016.12.037

19. Trotti A, Colevas AD, Setser A, Rusch V, Jaques D, Budach V, et al. CTCAE v3.0: development of a comprehensive grading system for the adverse effects of cancer treatment. Semin Radiat Oncol. (2003) 13:17681. doi: 10.1016/S1053-4296(03)00031-6

20. Kim TH, Cho KH, Pyo HR, Lee JS, Han JY, Zo JI, et al. Dosevolumetric parameters for predicting severe radiation pneumonitis after three-dimensional conformal radiation therapy for lung cancer. Radiology. (2005) 235:208-15. doi: 10.1148/radiol.2351040248

21. Arcangeli S, Agolli L, Portalone L, Migliorino MR, Lopergolo MG, Monaco A, et al. Patterns of CT lung injury and toxicity after stereotactic radiotherapy delivered with helical tomotherapy in early stage medically inoperable NSCLC. Br J Radiol. (2015) 88:20140728. doi: 10.1259/bjr.20140728

22. Choi YW, Munden RF, Erasmus JJ, Park KJ, Chung WK, Jeon SC, et al. Effects of radiation therapy on the lung: radiologic appearances and differential diagnosis. Radiographics. (2004) 24:985-98. doi: 10.1148/rg.244035160

23. Grant SW, Collins GS, Nashef SAM. Statistical Primer: developing and validating a risk prediction model. Eur J Cardiothorac Surg. (2018) 54:2038. doi: 10.1093/ejcts/ezy180

24. Lang RM, Badano LP, Mor-Avi V, Afilalo J, Armstrong A, Ernande L, et al. Recommendations for cardiac chamber quantification by echocardiography in adults: an update from the American Society of Echocardiography and the European Association of Cardiovascular Imaging. Eur Heart J Cardiovasc Imaging. (2015) 16:233-70. doi: 10.1093/ehjci/jev014

25. Ponikowski P, Voors AA, Anker SD, Bueno H, Cleland JGF, Coats AJS, et al. 2016 ESC Guidelines for the diagnosis and treatment of acute and chronic heart failure: The Task Force for the diagnosis and treatment of acute and chronic heart failure of the European Society of Cardiology (ESC) developed with the special contribution of the Heart Failure Association (HFA) of the ESC. Eur Heart J. (2016) 37:2129-200. doi: 10.1002/ejhf.592 
26. Bristow MR, Kao DP, Breathett KK, Altman NL, Gorcsan J III, Gill EA, et al. Structural and functional phenotyping of the failing heart: is the left ventricular ejection fraction obsolete? JACC Heart Fail. (2017) 5:77281. doi: 10.1016/j.jchf.2017.09.009

27. Federmann M, Hess OM. Differentiation between systolic and diastolic dysfunction. Eur Heart J. (1994) 15(Suppl D):26. doi: 10.1093/eurheartj/15.suppl_D.2

28. Bloom MW, Greenberg B, Jaarsma T, Januzzi JL, Lam CSP, Maggioni AP, et al. Heart failure with reduced ejection fraction. Nat Rev Dis Primers. (2017) 3:17058. doi: 10.1038/nrdp.2017.58

29. Yip G, Wang M, Zhang Y, Fung JW, Ho PY, Sanderson JE. Left ventricular long axis function in diastolic heart failure is reduced in both diastole and systole: time for a redefinition? Heart. (2002) 87:121-5. doi: 10.1136/heart.87.2.121

30. Petrie MC, Caruana L, Berry C, McMurray JJ. "Diastolic heart failure" or heart failure caused by subtle left ventricular systolic dysfunction? Heart. (2002) 87:29-31. doi: 10.1136/heart.87.1.29

31. Yu CM, Lin H, Yang H, Kong SL, Zhang Q, Lee SW. Progression of systolic abnormalities in patients with "isolated" diastolic heart failure and diastolic dysfunction. Circulation. (2002) 105:1195-201. doi: 10.1161/hc1002.105185

32. Dunlay SM, Roger VL, Weston SA, Jiang R, Redfield MM. Longitudinal changes in ejection fraction in heart failure patients with preserved and reduced ejection fraction. Circ Heart Fail. (2012) 5:720-6. doi: 10.1161/CIRCHEARTFAILURE.111.966366

33. Ueda T, Kawakami R, Nishida T, Onoue K, Soeda T, Okayama S, et al. Left ventricular ejection fraction (EF) of $55 \%$ as cutoff for late transition from heart failure (HF) with preserved EF to HF with mildly reduced EF. Circ J. (2015) 79:2209-15. doi: 10.1253/circj.CJ-15-0425

34. Smiseth OA, Torp H, Opdahl A, Haugaa KH, Urheim S. Myocardial strain imaging: how useful is it in clinical decision making? Eur Heart J. (2016) 37:1196-207. doi: 10.1093/eurheartj/ehv529

35. Hsu JJ, Ziaeian B, Fonarow GC. Heart failure with mid-range (borderline) ejection fraction: clinical implications and future directions. JACC Heart Fail. (2017) 5:763-71. doi: 10.1016/j.jchf.2017.06.013

36. Rastogi A, Novak E, Platts AE, Mann DL. Epidemiology, pathophysiology and clinical outcomes for heart failure patients with a mid-range ejection fraction. Eur J Heart Fail. (2017) 19:1597-605. doi: 10.1002/ejhf.879

37. Nagueh SF, Appleton CP, Gillebert TC, Marino PN, Oh JK, Smiseth OA, et al. Recommendations for the evaluation of left ventricular diastolic function by echocardiography. J Am Soc Echocardiogr. (2009) 22:10733. doi: 10.1016/j.echo.2008.11.023
38. Shuai XX, Chen YY, Lu YX, Su GH, Wang YH, Zhao HL, et al. Diagnosis of heart failure with preserved ejection fraction: which parameters and diagnostic strategies are more valuable? Eur J Heart Fail. (2011) 13:73745. doi: 10.1093/eurjhf/hfr053

39. Nagueh SF, Smiseth OA, Appleton CP, Byrd BF III, Dokainish H, Edvardsen $\mathrm{T}$, et al. Recommendations for the evaluation of left ventricular diastolic function by echocardiography: an update from the American Society of Echocardiography and the European Association of Cardiovascular Imaging. J Am Soc Echocardiogr. (2016) 29:277-314. doi: 10.1016/j.echo.2016.01.011

40. Dunsford ML, Mead GM, Bateman AC, Cook T, Tung K. Severe pulmonary toxicity in patients treated with a combination of docetaxel and gemcitabine for metastatic transitional cell carcinoma. Ann Oncol Aug. (1999) 10:9437. doi: 10.1023/A:1008377819875

41. Esteban E, Villanueva N, Muñiz I, Fernández Y, Fra J, Luque M, et al. Pulmonary toxicity in patients treated with gemcitabine plus vinorelbine or docetaxel for advanced non-small cell lung cancer: outcome data on a randomized phase II study. Invest New Drugs. (2008) 26:6774. doi: 10.1007/s10637-007-9073-4

42. Cowie MR, Jourdain P, Maisel A, Dahlstrom U, Follath F, Isnard R, et al. Clinical applications of B-type natriuretic peptide (BNP) testing. Eur Heart J. (2003) 24:1710-18. doi: 10.1016/S0195-668X(03)00476-7

43. Miyoshi H, Oishi Y, Mizuguchi Y, Iuchi A, Nagase N, Ara N, et al. Early predictors of alterations in left atrial structure and function related to left ventricular dysfunction in asymptomatic patients with hypertension. J Am Soc Hypertens. (2013) 7:206-15. doi: 10.1016/j.jash.2013.02.001

44. Maragiannis D, Nagueh SF. Echocardiographic evaluation of left ventricular diastolic function: an update. Curr Cardiol Rep. (2015) 17:3. doi: 10.1007/s11886-014-0561-9

Conflict of Interest: The authors declare that the research was conducted in the absence of any commercial or financial relationships that could be construed as a potential conflict of interest.

Copyright (c) 2020 Cai, Liang, Li, Meng and Yu. This is an open-access article distributed under the terms of the Creative Commons Attribution License (CC BY). The use, distribution or reproduction in other forums is permitted, provided the original author(s) and the copyright owner(s) are credited and that the original publication in this journal is cited, in accordance with accepted academic practice. No use, distribution or reproduction is permitted which does not comply with these terms. 